\title{
LUT
}

University

\section{A Critical Comparison of Two Creativity Methods for Fostering Participatory Innovation: Implications to Improve TRIZ}

\author{
Nisula Anna-Maija, Kianto Aino
}

This is a Author's accepted manuscript (AAM) version of a publication published by Springer, Cham

in Advances and Impacts of the Theory of Inventive Problem Solving

DOI: $10.1007 / 978-3-319-96532-1 \_4$

Copyright of the original publication: ( ) Springer Nature Switzerland AG 2018

Please cite the publication as follows:

Nisula AM., Kianto A. (2018) A Critical Comparison of Two Creativity Methods for Fostering Participatory Innovation: Implications to Improve TRIZ. In: Koziołek S., Chechurin L., Collan M. (eds) Advances and Impacts of the Theory of Inventive Problem Solving. Springer, Cham. DOI: 10.1007/978-3-319-96532-1_4

This is a parallel published version of an original publication. This version can differ from the original published article. 


\title{
A critical comparison of two creativity methods for fostering participatory innovation: Implications to improve TRIZ
}

\author{
Anna-Maija Nisula *) \\ Post-doctoral researcher \\ anna-maija.nisula@lut.fi
}

Aino Kianto

Professor

aino.kianto@lut.fi

School of Business and Management,

Lappeenranta university of Technology,

Lappeenranta

Finland

*) corresponding author

\begin{abstract}
We present an empirical study in which we contrast two creativity methods, the lateral thinking method and the improvisational theatre method, to investigate their applicability for advancing participatory innovation. While both of the contrasted methods aim to increase creativity as a means of improving participative innovation, they differ in terms of their conceptualisations of creativity, goals and processes. We propose that these two methods could complement the weaknesses of the TRIZ method (theory of inventive problem solving), especially in cases in which diverse experts gather to innovate, solve problems and generate new knowledge for shared goals. We illustrate the utilisation of the methods by reporting two creative development workshops. The paper sheds light on methods for fostering creative participatory innovation and highlights the collective nature of co-creation in participatory innovation. In addition, the paper suggests how the studied participative co-creative methods could be useful in improving the TRIZ method.
\end{abstract}

Keywords: participatory innovation, creativity, Lateral thinking, improvisational theatre

\section{Introduction}

In today's business environment, companies compete to survive and succeed in a relentless quest for continuous innovation. An increasing number of innovations result from intense collaboration and the integration of the knowledge and perspectives of diverse actors (e.g. Catmull 2008; Harvey 2014; Robbins and O'Gorman 2014), in which the contributions and participation of all actors are vital. Thus, companies desire input from diverse actors, such as employees, customers, users and other external stakeholders, to increase their innovation pace. Scholars have used terms like co-innovation (Romero and Molina 2009), employeedriven innovation (Bessant et al. 2001; Kesting and Ulhoi, 2010), high-involvement innovation (Bessant 2003; Bessant and Caffyn 1997; Tidd and Bessant 2009), user-driven innovation (Griffin and Hauser 1993; von Hippel 1988) and participatory innovation (Buur 
and Matthews 2008) to emphasise the idea that novel ideas and innovations result from intense collaborations among diverse actors (Dougherty and Dunne, 2011; Hargadon and Bechky, 2006; Harvey, 2014). However, there exists less knowledge on how the participation of such diverse actors in innovation can be enabled, motivated and supported.

Creativity is the key driver of innovation (Amabile 1983; Oldham \& Cummings 1996; Styhre and Sundgren 2005). Therefore, a variety of creativity-stimulating methods are widely used in innovation management. One of the most well-known methods is the theory of inventive problem solving (TRIZ) (Altshuller 1999). TRIZ represents a systematic way of thinking (Ilevbare, Probert and Phaal 2013) and a methodology to foster creativity for innovation and inventive problem solving, especially in technology inventions. TRIZ relies on the assumption that technology development and invention are predictable and governed by certain laws (Savranksy 2000; Ilevbare et al., 2013).

However, TRIZ tends not to explicitly consider the stimulation of participation: that is, the empowerment and acknowledgement of diverse actors' creative contributions to innovation development. This is problematic, as scholars suggest that a sufficient environment and climate for idea generation enhances employees' participation in innovation (Kesting and Ulhoi, 2010). Moreover, the invention and development of radically new products and services - something that does not exist - often involves complex, fuzzy, non-linear and unpredictable processes (e.g. Harvey, 2014; Arnold and Barth 2012; Dougherty and Dunne, 2011). These findings, together with research showing that multiple aspects of innovation often require intense and fluent communication and collaboration among different actors (e.g. Harvey, 2014; West and Bogers 2013), may challenge such systematic approaches to innovation as TRIZ.

In line with a study by Ilevbare et al. (2013), we suggest that participation-supporting creativity methods could be of use and value to TRIZ for a number of reasons. First, in a highly competitive business environment, accelerating innovation is essential, and companies need faster methods to produce innovations. TRIZ, as a relatively rigid method (Ilevbare et al. 2013), may not support the innovative speed necessary in such invention processes. Second, the complexity of TRIZ means that practitioners must have a deep understanding of and experience with the method before they can achieve effective results (Ezickson 2005). Thus, beginners cannot use TRIZ fluently until they have learned it. In terms of participative innovation, therefore, the use of TRIZ may decrease possibilities to contribute among those who are unfamiliar with TRIZ. Third, innovative teams are increasingly multi-expert (i.e. composed of people from different fields of expertise) and temporary: groups of people gathered together to collaborate on a particular problem. As TRIZ is highly technologyoriented and requires learning, it may be difficult for non-tech members and temporary members to adopt.

To increase our understanding of the facilitation of participatory innovation, we compare two methods for fostering creativity: the lateral thinking method (de Bono 1992) and the improvisational theatre method. While the lateral thinking method is a cognition-based and structured approach to idea generation, improvisational theatre is an art-based method that emphasises the emergent nature of collective creation (Sawyer and DeZutter 2009). Critically comparing these two methods is a fruitful approach to increase our understanding of the role of creativity and ways to support it in participatory innovation. The comparison also increases our understanding of the suitability and limitations of the two methods for fostering participatory innovation in organisations. Thus, by comparing these two methods, we shed light on the enablers of participatory innovation and discuss the advantages of each method for fostering creativity and innovation. Thereafter, we discuss implications for participative innovation and the systematic TRIZ method. Specifically, we suggest the two studied methods can serve and complement the identified weaknesses of the technology-oriented TRIZ method (see Ilevbare, Probert and Phaal 2013). 


\section{Theoretical background}

\subsection{Participatory innovation}

Participatory innovation (Buur and Matthews 2008), or high-involvement innovation (Bessant 2003; Bessant and Caffyn 1997; Hallgren 2009), refers to the realisation of the potential of organisational employees and various other stakeholders to generate and implement novel ideas to achieve improvements, develop new products and processes and organise work and changes. In product development involving designers/producers and users, participative innovation is often described as participatory innovation (Buur and Matthews 2008), which term we use also in the present study. Participative innovation is rooted in an overall ability to enable, motivate and support a wide set of actors to contribute to the development and application of new ideas, improvements and innovations (Bessant 2003; Bessant \& Caffyn 1997; Hallgren 2009).

Participatory innovation is a joint activity through which solutions emerge through the constructive integration of differences and perspectives. A fundamental characteristic of participative innovation is the full empowerment of various stakeholders in co-creation and innovation activities throughout the entire innovation process, whether this involves sourcing data on user needs or collecting insights from front-line employees. This kind of functioning refers to the behavioural patterns, practices and cultures in an innovation group or environment that focus conscious attention on empowering participants in innovation and developmental processes to ensure that ideation, problem finding and problem solving are activities that belong to all participants.

The stimulation of the creative potential and participation of individuals and groups should consider several aspects. Firstly, it should facilitate the creative contributions of participating individuals, that is, generation, voicing, development and realisation of ideas. Second, it should build suitable conditions for creative interactions among people to enable the emergence of group power, since creative contributions (i.e. idea generation, development and realisation) occur through social interactions among participating members. More specifically, the voiced ideas of others often trigger associations and build novel connections in individuals' thoughts (Guilford, 1950; John-Steiner 2000; Paulus and Yang 2000), and enable individuals to build on others' ideas, thereby increasing participation. In addition, the creative process is unpredictable and subject to unexpected turning points, which can also increase participation (i.e. contributions from stakeholders).

\subsection{Comparing the improvisational theatre-based and lateral thinking methods}

The improvisational theatre-based method is an art-based method that emphasises the emergent nature of collective creation (Friis 2006; Nisula and Kianto [in press]; Sawyer and DeZutter 2009). More specifically, an improvised theatre emphasises participation and the collective process of co-creation as they play out in mutual and intense interactions among participating members (Johnstone 1996; Koppett 2001; Spolin 1977; Weick 1993; Yanow 2001).

The lateral thinking method (De Bono 1992; Provost and Sproul 1996) aims to increase participants' potential to identify ideas outside normal thinking patterns through a structured approach in which divergent and convergent thinking are promoted in an iterative fashion. As an idea generation method, it supports the creative thinking component (Amabile 1998) of creativity.

In the following, we contrast these two methods in terms of their points of view on creativity and their backgrounds, goals, processes, principles and possibilities with respect to participate the people involved in the innovation process. Table 1 compares the key characteristics of the two methods. 
Table 1: Comparison of lateral thinking and improvisational theatre methods.

\begin{tabular}{|c|c|c|}
\hline & Lateral thinking (de Bono, 1992) & Improvisational theatre based method \\
\hline Creativity & Serious, deliberate and systematic & $\begin{array}{l}\text { Freeing imagination, i.e. combination } \\
\text { of imagination, improvisation, } \\
\text { intuition, emotions, passion, } \\
\text { motivation }\end{array}$ \\
\hline Background & Individual cognitive creative thinking & $\begin{array}{l}\text { Art-based method. Holistic and social } \\
\text { systemic view including both } \\
\text { individual and collective creativity }\end{array}$ \\
\hline Goal of the method & $\begin{array}{l}\text { Improving the width and depth of } \\
\text { thinking }\end{array}$ & $\begin{array}{l}\text { Developing creativity, imagination and } \\
\text { improvisational abilities (individual } \\
\text { and collective) }\end{array}$ \\
\hline Process & Structured (step-by-step) process & $\begin{array}{l}\text { Non-structured } \\
\text { Enables event and case driven } \\
\text { development path (tailor-made) }\end{array}$ \\
\hline $\begin{array}{l}\text { Objective of the } \\
\text { Process }\end{array}$ & Defined or given in a question form & Not clearly defined problem(openness) \\
\hline Interaction & $\begin{array}{l}\text { Acknowledges both individual and } \\
\text { group working }\end{array}$ & $\begin{array}{l}\text { Acknowledges both pair and group } \\
\text { working }\end{array}$ \\
\hline Climate for creativity & Not supported & $\begin{array}{l}\text { Strong efforts in building climate for } \\
\text { creativity }\end{array}$ \\
\hline Group cohesion & Not supported & $\begin{array}{l}\text { Strong efforts in building group } \\
\text { cohesion }\end{array}$ \\
\hline Individual skills & Broadening thinking skills & $\begin{array}{l}\text { Triggers to recognize limiting thought } \\
\text { patters, mental models and behaviours }\end{array}$ \\
\hline Key principles & $\begin{array}{l}\text { Extending thinking by asking questions } \\
\text { are there other ways to carry out the same } \\
\text { idea, are there ways to accomplish the } \\
\text { same objective }\end{array}$ & $\begin{array}{l}\text { Building on others ideas ('yes, and...') } \\
\text { Utilizing whatever (emotions, } \\
\text { imagination, environment, intuition) as } \\
\text { material for performance } \\
\text { Shared responsibility and leadership }\end{array}$ \\
\hline Utilization & $\begin{array}{l}\text { Effective tool to collect ideas from } \\
\text { particular theme of problem. } \\
\text { Can be used also individually in daily } \\
\text { life. }\end{array}$ & $\begin{array}{l}\text { Improving both individual and } \\
\text { collective creativity } \\
\text { Organizational development } \\
\text { Fostering organizational creativity } \\
\text { Can be adopted as a personal behaviour }\end{array}$ \\
\hline
\end{tabular}

\subsubsection{Creativity}

Improvisational theatre follows an art-based approach to creativity. In improvisational theatre, creativity is understood as a process that integrates people's ideas, contributions, imagination, interactions and collective meaning creation, as well as such factors as environmental influences, timing, fortune and mistakes. Rather than seeing creativity as a linear process, improvisational theatre views creativity as distributed (Sawyer and DeZutter 2009) or as a rhizome, such that horizontally dispersed knowledge can be connected to any node (Deleuze and Guattari 1988; Styhre and Sundgren 2005). Thus, creativity is rooted in connections and collective activity (Bissola and Imperatori 2011; West and Altik 1996). In addition, improvisational theatre also highly emphasises individuals' ability to imagine, utilise their interpersonal creativity and contribute to the collective processes of creation. 
The lateral thinking method describes creativity as serious, deliberate and systematic, rather than artistic, natural talent or 'acting crazy' (De Bono 1992; Provost and Sproul 1996). De Bono (1992) and Provost and Sproul (1996) highlight the difference between artistic (natural talent) creativity and serious creativity in the lateral thinking method. In the lateral thinking approach, individuals are seen as key sources of ideas. Similarly, West and Richter (2011) understand individual creativity as idea generation: that is, a process involving an individual's creative characteristics (compared to innovation, which involves the implementation of these ideas in practice). However, in lateral thinking, creativity is seen as a fundamental basis for improving activities in organisations, for supporting problem solving and innovations and for securing full use of existing knowledge. More specifically, the lateral thinking method fosters the creative thinking component (Amabile 1998) of creativity.

\subsubsection{Goal}

The improvisational theatre-based method aims to develop both individual and group interactions and to empower participants through collective creation. It uses several different kinds of exercises or techniques to foster joint idea generation. In improvisational training, rational goals are seldom used during the initiative steps of the training. Thus, the outcomes of improvisational workshops are seldom concrete numbers of ideas; rather, such workshops yield intangible outcomes, such as improved communication, interaction, group cohesion, climate for creativity and freedom to imagine and contribute to collective creation, but also collectively generated idea.

By contrast, the lateral thinking approach is goal- and outcome-oriented and designed to be applied to particular and well-defined themes or problems. Its results include the production of a number of ideas and concepts around a given problem. At best, a session designed to address a specific problem will produce one or a few potential solutions for further development and testing and to serve as the basis for decision making.

\subsubsection{Process}

The improvisational theatre-based method provides flexibility in fostering creativity. Although it utilises a ready-made set of exercises, it is always tailor-made for each case and the primary purpose of the training. Planning an improvisational theatre-based session begins with identifying the participants. Training sessions usually start with a 'warm-up' period. If the participants involved do not know one another, training may also include 'getting to know one another' and 'ice-breaker' activities. In general, the purpose of improvisational theatrebased training is to define what constitutes a process. For example, if the aim is to foster communication and interaction within the work community, more weight is placed on exercises supporting these aims. Building team cohesion may form another combination of exercises. In addition, the content is influenced by participants' expertise. In other words, there is a difference between a process designed for beginners and one designed for more advanced improvisers. Indeed, improvisational theatre fruitfully models social interactions in which meaning emerges from intentions, actions and responses (Friis 2006).

The lateral thinking method follows a systematic process (Fig. 1) that begins with a problem definition or a given problem (the objective of idea generation) and continues with a divergent thinking phase. Individual idea generation initiates the process, and this is followed by a conceptualisation of ideas either in pairs or in groups. During this process, it is possible to add new ideas. Individual ideation is used to avoid social loafing, in which only a few people contribute while others remain passive spectators. In addition, distractions to individual ideation (e.g. social influences by others) should be avoided. Others' ideas are seen not as welcomed triggers, but as cueing and limiting disturbances to individual ideation. Furthermore, working individually is utilised to avoid social inhibitions (e.g. feeling uncomfortable in groups) (Provost and Sproul 1996). During the subsequent convergent 
thinking phase and throughout the evaluation, selection and development of ideas, one or a few possible solutions are selected for testing. The convergent thinking phase can be carried out as group work or can be done by the problem owner. Throughout the process, variations may be caused by the choice of different kinds of supporting tools, such as provocations, random entries or challenges, which can be introduced during different stages of the process as needed. The advantage of the lateral thinking method is its ability to survey a diversity of individual experiences and opinions.

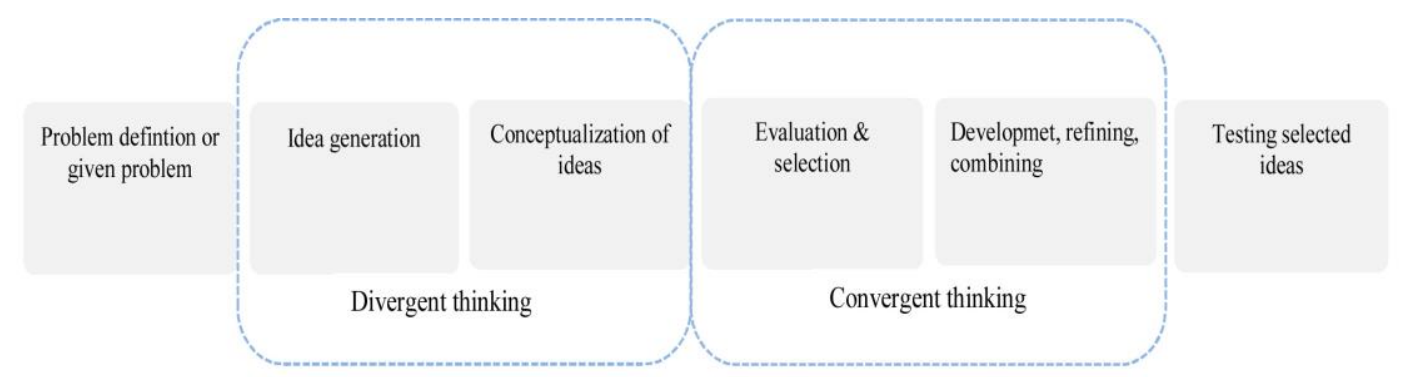

Figure 1: Lateral thinking process.

\subsubsection{Interaction}

Improvisational theatre emphasises the social relations and interactions among participating members throughout the workshop. Indeed, all exercises are carried out in pairs or in groups, during which participants focus on listening, awareness and communication (including nonverbal communication). By breaking conventional social behaviours and offering a new set of rules for social interaction, improvisational trainings enable participants to discover and recognise their limiting thought patterns, mental models and behaviours.

By contrast, the lateral thinking method does not pay any attention to interaction, social relations or trust-building among participating members, although it alternates between individual and group work. An individual who struggles to produce ideas during individual idea generation phases due to strong internal criticisms or a lack of familiarity with idea production may find the lateral thinking method frustrating. However, some individuals prefer to generate ideas alone, and they may appreciate the opportunity for individual idea generation. Next, during the group work phase, participants work together to organise ideas under concepts and to generate ideas that build on what has already been presented. Furthermore, idea extraction and evaluation can be conducted as group work.

\subsubsection{Climate for creativity}

Building a climate for creativity is fundamental for improvisational theatre. By building trust and stimulating team cohesion, mutual support and a sense of shared leadership and responsibility, improvisational theatre, at best, invites participants to contribute openly. By contrast, the lateral thinking method does not focus on building a climate for creativity and participation. 


\section{Methodology}

This study adapts a qualitative research approach to investigate the applicability of two distinct creativity methods for fostering participatory innovation. Qualitative research typically answers 'how' questions (Yin 1994, 2003). More specifically, to examine how lateral thinking and the improvisational theatre-based method can be used to further participative innovation, we execute innovation workshops with both methods. In addition, we use comparison as an approach to reveal the similarities and differences between the two methods.

We collected data from two creativity workshops carried out among the personnel of a research unit. Each workshop lasted approximately 2.5 hours. We interviewed the participants after each exhibit, conducting eight participant interviews in the lateral thinking workshop and seven participant interviews in the improvisational theatre workshop. Each interview lasted approximately 13 to 35 minutes. In addition, we used the recorded reflection discussions and group work sessions as supplementary research data.

The interview data were transcribed and analysed using content analysis. We were interested in the participants' perceptions and experiences of the two workshops. During the interviews, we asked about how the participants experienced the workshops, how each method fostered creativity, whether the participants experienced any difficulties during the workshops, what the participants learned, what the key outcome of the workshops was and where the participants would use the workshopped method in the future.

The first author of this paper acted as a facilitator in both workshops, and the second author took part in the demonstrations as a participant.

\section{Workshop 1: Improvisational theatre}

The improvisational theatre-based workshop was based on improvisational theatre exercises that are widely known and used in improviser communities (Johnstone 1979; Koppett 2001) and improvisational training courses in which the responsible author has participated. Appendix I presents the events in the improvisational theatre workshop. This workshop included basic exercises, starting with warm-up trainings and followed by trainings concentrating on the key principle of improvisational theatre: agree, accept and add (known also as 'yes, and...'). More specifically, these exercises focused on the fundamental improvisational principle of building on others' ideas. Telling a common story one word at time is an exercise that illustrates the distributed creativity, real-time action and spontaneity of such activities. The core nature of improvisational theatre is that creation happens through real-time interactions between participants and their context and that emergence is impossible for a single participant to control.

\section{Workshop 2: Lateral thinking}

The lateral thinking-based workshop began with the definition of a problem (i.e. the objective for the session; Table 2). The problem was described in the form of a question: 'How could we develop our future living?' The idea generation phase began with individual ideation, during which each participant contributed individual ideas on Post-It notes. The extraction phase involved a conscious and systematic organisation of ideas and concepts. The lateral thinking process uses a variety of additional tools, such as individual ideation triggered by random entry or provocation. In random entry, an individual blindly points to a random word from a list of words and uses it to trigger ideation. In provocation, negative and reverse wording are used to force a shift away from familiar thinking patterns. The six hat tool is an approach to parallel group thinking in which, for example, a selected solution is evaluated through different perspectives (colours or hats; de Bono, 1992), such as, from the perspective 
of objective data, by asking why the solution may work and why the solution may not work, possibilities as well as by identifying feelings. In this demonstration workshop, we did not continue the process until the end, when the few most promising ideas would usually be prioritised and selected for further development or testing.

Table 2: Events in the lateral thinking workshop

\begin{tabular}{r|l|l|l|l} 
& Lateral Thinking Process & Content & Type & Tools \\
\hline 1. & $\begin{array}{l}\text { Defining objective or modifying } \\
\text { given objective } \\
\text { 2. }\end{array}$ & $\begin{array}{l}\text { Objective in question form "How could } \\
\text { we improve ...” } \\
\text { Individually producing ideas and } \\
\text { putting ideas into post-its }\end{array}$ & group & individual \\
3. & Concept behind each idea & Ways to .... & $\begin{array}{l}\text { Provocation, } \\
\text { Random } \\
\text { entry }\end{array}$ \\
4. & Extending Concepts & Are there other ways to ... & group \\
5. & Concept Extraction & individual/group & group or case owner \\
6. & Selecting Solution & group or case owner & Six hats
\end{tabular}

\section{Findings}

In the following, we discuss the key findings concerning the similarities and differences in participants' impressions about the two different methods for facilitating participative innovation.

\subsection{Improvisational theatre-based creativity stimulation}

The improvisational theatre-based workshop comprised several small exercises. It started with warm-up and ice-breaker exercises that involved the whole group. During the warm-up exercises, we accepted and celebrated failures, which the participants considered a lot of fun and very enjoyable. After each exercise, we briefly reflected on the feelings and experiences of both the participants and the facilitator. As facilitator, I also shared the key idea of each exercise. From the very beginning of the workshop, the participants were laughing and smiling, and it seemed that they enjoyed the exercises. After the warm-up, we engaged in the basics of improvisation: namely, exercises involving 'agree-disagree' and 'agree, accept and add'. These were carried out in pairs, while the 'yes, but...' exercises were carried out in groups of five or six people. The word-by-word story telling was challenging. Following a reflective discussion, during which mistakes and problems were collectively shared and discussed, the participants expressed a desire to tell another story by carefully listening to others. During the final discussion, the participants felt very positive and inspired. However, few expressed missing concrete results, such as a number of generated ideas or other useful outcomes.

\subsubsection{Participants' experiences}

Without exception, the participants experienced the workshop as fun and playful. All expressed having positive feelings during and after the exercises. 


\subsubsection{Supporting creativity}

The respondents felt relaxed and able to throw into experiencing and discuss their experiences. One respondent considered the workshop effective in helping them get to know one another:

In two hours, you learn more about others - in telling a common story or in making offers for others [agree-disagree]-than in working two months in the same working place. I feel that it tells 'between the lines' how people think and act and even such things that one does not necessarily have thought-however, it becomes conveyed.

You get to know people, and the setting is so informal. There is no formality like in the meeting room, and you learn whole new things about people.

The participants also found that the experience created common understanding and team cohesion, as the following quote describes:

It can be used to test what this group could be capable of when working together. Perhaps it's not so much producing something new. It's more like reinforcing the group; bringing the individuals together.

\subsubsection{Learning}

The participants learned about themselves and found that they were capable of spontaneous contributions. As one participant noted: '... but I noticed that I am able to express something spontaneously...' The participants also learned to see group work in a new light. As one participant described:

It also taught me to work in a group, because whenever I'm in a group situation, when everyone else is quiet, I feel like I have to do something. Now I had to listen-and just noticing how little you can influence the story when everyone has to contribute one by one, and noticing that you can't dictate how the story goes-it makes you remember that you're always only a little part of the group.

\subsubsection{The key outcomes of the method}

The key outcomes of the improvisational theatre workshop included freeing and encouraging individuals to experience, throw themselves into situations and contribute, as the following quotes describe:

Practicing it could make it easier to get more involved, forget about any inhibitions and just let go!

And when you get into a creative mood, a playful state, it absolutely frees you, because they break old routines and the tacit front end of innovation. It could work really well as a warm-up exercise before systematic idea generation.

The participants also felt that the improvisational training models stimulated social interaction and collective creation. As one participant described:

It's useful for the kind of social interaction that is essential in innovation and all work. It nicely incorporates joint idea generation and the social aspect of creativity.

The participants noticed that, through practice, they could achieve much more in social interaction.

\subsection{Lateral thinking method-based stimulation of participative innovation}

The lateral thinking exhibit began with the participants choosing a target topic from two alternatives. We discussed and modified both topics to be suitable for the exhibit and 
collectively elected the choice 'How could we advance more sustainable building and city living?' The process began with individual idea generation, during which each participant individually generated ideas by putting them on the Post-Its (one idea per Post-It). After a few minutes, I, as a facilitator, introduced random entry and provocation tools to trigger further idea generation. We continued the individual idea generation for a few minutes. Thereafter, the participants were grouped into pairs and started to build idea concepts from their Post-Its (i.e. they grouped similar kinds of ideas under similar concepts). They also added new emerging ideas or concepts. Following this pair group work, the idea concepts were put on the wall. We all began to look at the ideas and to see what the other groups had produced. Though the ideas mostly dealt with the same phenomenon, one pair was surprised about one of the developed idea groups, which they had not considered. The concepts were then grouped again (i.e. similar kinds of concepts were connected), and new ones were created. Next, the ideas and idea groupings were be re-worked in order to reduce concepts and select possible solutions for further development. During the short discussion after the session, the participants expressed missing real collective idea generation, in which someone else's ideas can trigger one's own idea generation.

\subsubsection{Participants' experiences}

The lateral thinking method was considered familiar and even traditional, given its similarities to several other methods for collecting and generating ideas both individually and in groups. The respondents experienced the process as individual-driven and felt that that it did not utilise the power of the group from the early steps of the process. This consensus is described in the following two quotes:

The fact that people were in the same room was not really taken advantage of. I feel that we would have got the same number of ideas if we had been alone in our offices and written down our ideas.

It was all based on what we had written down by ourselves. I had the feeling that nothing special had happened.

\subsubsection{Supporting creativity}

The respondents found that the lateral thinking method was not creative. As one participant explained:

Perhaps it's the fooling around that has associations with creativity! I just had a bit higher expectations.

Some of the participants experienced the individual idea generation phase as difficult. For example:

The topic was wrong for me personally. I couldn't come up with ideas. It felt difficult, and I realised that they weren't all that original. I saw that others came up with some good ideas, but the topic just felt alien to me.

Others were more familiar with individual ideation:

At first, it felt great working alone, but then the ideas just ended, and when we started working with a partner, the ideas started coming again, and the tools [random word entry and provocation] even increased it. It may not be suitable for everyone, but for me, it's perfect.

The use of tools, including random word entry and provocation, was seen as triggering creativity. 


\subsubsection{The key outcomes of the method}

The lateral thinking method was considered suitable and effective for surveying and collecting ideas using simple techniques in a short time. However, the participants did not see this process as having the potential to support the creation of radical and totally new openings.

\section{Discussion}

In this chapter, we discuss the findings from the point of view of participative innovation. Participative innovation demands the empowerment of diverse actors in the generation of novel outcomes. Thus, the critical question is: How can we best empower and stimulate such wide participation in innovation activities?

The two methods studied in the present study differ in their potential to encourage and empower the full participation of the people involved. The improvisational theatre-based method encourages participants to engage in spontaneous contributions by accepting failures and building on others' ideas. As a form of emergent joint creation, it fosters playfulness, engagement and full participation throughout the creation process. By contrast, the lateral thinking approach shifts between individual and group work, taking advantage of the wide diversity of individual ideas and experiences. This method is also, by nature, an idea generation method, as it aims to increase the number of generated ideas; therefore, it does not focus on ensuring full participation throughout the co-creation process.

Concerning the role of creativity in fostering participatory innovation, we explored how idea generation, development and realisation in practice are supported and facilitated. In improvisational theatre, creativity is understood as a holistic and collective social activity and as being essentially embedded throughout the innovation process. In this respect, improvised theatre better responds to the purposes of participatory innovation because it builds suitable conditions (i.e. climate and social connectivity) for people to contribute and engage in innovation. Simultaneously, it develops the participating members' abilities to contribute to the collective creative process. By contrast, in the lateral thinking method, creativity is conceptualised as idea generation (de Bono 1992; Provost and Sproul 1996; West and Richter 2011). Specifically, this approach provides a tool to extend thinking (divergent thinking) and, thereafter, to compose ideas (convergent thinking). This method is useful during the front end of innovation and, in particular, for problem solving situations; however, it does not foster participation throughout the innovation process. As a result, participatory development and the implementation (realisation) of ideas in practice may suffer.

The primary obstacle to creativity is individuals themselves. If individuals consider themselves 'not creative', it may prevent their contributions to situations that require creativity and activities outside of their comfort zones. For participatory innovation to occur, it is fundamental for the people involved to use their potential and contribute to the innovation process. In this respect, the methods that aim to increase participants' creativity can increase the likelihood that they will engage in innovation. More specifically, individuals' beliefs that they can perform creative actions evolve through positive experiences. Creativity training can provide such positive experiences and, thus, serve as a starting point for increased participation. In general, people will opt to perform tasks in which their competency beliefs are high and to avoid tasks in which they anticipate their performance skills to be low (Bandura 1997). These tendencies can be addressed and rewired through training. By offering participants experiences of being creative, either through generating and selecting ideas (lateral thinking) or engaging in playful co-creation (improvisational theatre). Thus, both of the methods examined in this research have the potential to increase participants' likelihood of engaging in future creative behaviours. 
Furthermore, as both individual attributes and contextual factors influence participative innovation, facilitation methods should capture both of these levels simultaneously. The improvisational theatre method focuses on building sufficient circumstances and climates for creative interactions to enable the emergence of group power. It is rooted in collective improvisation, in which co-creation happens through social interactions among participating members. By contrast, in the lateral thinking method, conditions for interaction are built through the iterative use of both individual and group work.

Concerning the nature of the innovation process, the studied methods take nearly opposite views. The improvisational theatre-based process is a non-linear innovation process rooted in the rhizome nature of knowledge. In this approach, any idea or contribution can be connected to any previous idea or contribution, and the process outcome is somewhat open-ended. This enables individuals to build on others' ideas and develop single ideas further. Therefore, the improvisational theatre-based approach provides more flexibility and allows for the occurrence of radical turning points. By contrast, the lateral thinking method is a structured and step-by-step process that yields a huge number of ideas and some potential solutions as outcomes.

Drawing from these two examined methods, we suggest that the improvisational theatre-based method develops participants' capabilities to interact, openly share their ideas and experiences and build on the ideas of others, thereby promoting connectivity, continuous exchange and dialogue among participating members. Improvisational theatre is also a powerful method of empowering and committing participants that can increase participation in innovation. By contrast, the lateral thinking method is a viable method to use in particular problem situations and at the beginning of the participatory innovation process, when it is necessary to collect a broad array of ideas. However, this method does not focus on committing members to participating in idea development and implementation in practice.

\section{Conclusion}

In this paper, we investigated two approaches to fostering creativity in participatory innovation. These two methods, which represent different backgrounds, views of creativity and goals and processes, offer different possibilities to facilitate participatory innovation. While the improvisational theatre-based method is powerful for building a conducive climate and strong social, communicative and creative interactions among participants, the lateral thinking method is effective for surveying and organising ideas within a particular problem field.

Our study increases our understanding of the applicability of the creativity-stimulating improvisational theatre-based and lateral thinking methods for fostering participatory innovation. In so doing, it sheds light on the critical enablers of participatory innovation. Our findings contribute to earlier research (e.g. Harvey 2014; Buur and Matthews, 2008) by suggesting that, when attempting to stimulate actors' participation in the generation of novel outcomes, it is necessary to examine the social dimension and the collective and emergent nature of co-creation in participatory innovation. This finding is particularly important in relation to systematic and structured processes of innovation, like TRIZ (Savransky 2000).

Our study contributes to the identified weaknesses of the TRIZ method (e.g. Ilevbare et al., 2013) by suggesting that while aiming to increase speed in innovation, the innovation managers should understand innovation process as flexible and use facilitation or creativity methods that enable desired speed in innovation. In addition, the method should be easy to implement with beginners or temporary participants. To accomplish these goals, the TRIZ procedure could incorporate more participative elements in order to increase possibilities for customers or other members who may be unfamiliar with the method to contribute. Innovation results from intense collaboration and the integration of the knowledge and perspectives of diverse actors (e.g. Catmull 2008; Harvey 2014; Robbins and O'Gorman 2014,), who are not 
always technology-oriented. Thus, the technology-oriented TRIZ method may need to be adapted to include practices that support the integration of diverse perspectives.

The managerial contribution of the paper highlights the strengths and weaknesses of each method in terms of participatory innovation by showing how the spectrum of available methods enables practitioners to develop more tailored and case-sensitive methods for facilitating participatory innovation. Indeed, to stimulate the development of participative innovation, practitioners require a set of methods that empower the creative potential of diverse participants by building a climate and energy suitable for joint creative processes.

Our research involved several limitations that should be addressed by future studies. Firstly, our study involved only one exhibit each for the two creativity methods. As our goal was to investigate the potential of these two creativity methods to stimulate the participation of diverse actors in innovation, we believe that our comparison represents a good first step in shedding light on the methods' ability to boost participation. However, future studies should explore these methods via multiple cases and with different types of participants. In addition, future studies should explore a wider set of creativity-supporting methods, including creativity tools from the TRIZ toolset.

\section{REFERENCES}

Altshuller, G. (1999). The innovation algorithm: TRIZ, systematic innovation and technical creativity. Technical Innovation Center, Inc.

Amabile, T. M. (1983). The social psychology of creativity: a componential conceptualization. Journal of Personality and Social Psychology, 45(2), 357-376.

Amabile, T. M. (1998). How to kill creativity (Vol. 87). Boston: Harvard Business School Publishing.

Arnold, M., \& Barth, V. (2012). Open innovation in urban energy systems. Energy Efficiency, 5(3), 351-364.

Bandura, A. (1997). Self-efficacy: the exercise of control. Macmillan.

Basadur, M., Pringle, P. Speranzini, G., \& Bacot, M. (2000). Collaborative problem solving through creativity in problem definition: expanding the pie. Creativity and Innovation Management, 9(1), 54-76.

Bessant, J. (2003). Challenges in innovation management. The International Handbook on Innovation, 761774.

Bessant, J., \& Caffyn, S. (1997). High-involvement innovation through continuous improvement. International Journal of Technology Management, 14(1), 7-28.

Bessant, J., Caffyn, S., \& Gallagher, M. (2001). An evolutionary model of continuous improvement behaviour. Technovation, 21(2), 67-77.

Bissola, R., \& Imperatori, B. (2011). Organizing individual and collective creativity: flying in the face of creativity clichés. Creativity and Innovation Management Journal, 20, 77-89.

Buur, J., \& Matthews, B. (2008). Participatory innovation. International Journal of Innovation Management, 12(3), 255-273.

Catmull, E. (2008). How Pixar fosters collective creativity. Cambridge: Harvard Business School Publishing.

de Bono, E. (1992). Serious creativity. Using the power of lateral thinking to create new ideas. Fontana: HarperCollins Publishers.

Deleuze, G., \& Guattari, F. (1988). A thousand plateaus: capitalism and schizophrenia. Minneapolis: University of Minnesota Press. 
Dougherty, D., \& Dunne, D. D. (2011). Organizing ecologies of complex innovation. Organization Science, 22(5), 1214-1223.

Ezickson, J. (2005). Deploying innovation and inventive thinking in organisations - applying TRIZ to nontechnical fields of business. TRIZCON2005. http://www.aitriz.org/articles/InsideTRIZ/30393033457A69636B736F6E. Accessed 30 Nov 2011.

Friis, P. (2006). Presence and spontaneity in improvisational work. In P. Shaw, \& R. Stacey (Eds.), Experiencing risk, spontaneity and improvisation in organizational change. Routledge: Taylor \& Francis Group.

Griffin, A., \& Hauser, J. R. (1993). The voice of the customer. Marketing Science, 12(1), 1-27.

Guilford, J. P. (1950). Creativity. American Psychologist, 5(9), 444-454.

Hallgren, E. W. (2009). How to use an innovation audit as a learning tool: a case study of enhancing highinvolvement innovation. Creativity and Innovation Management, 18(1), 48-58.

Hargadon, A. B., \& Bechky, B. A. (2006). When collections of creatives become creative collectives: a field study of problem solving at work. Organization Science, 17(4), 484-500.

Harvey, S. (2013). A different perspective: the multiple effects of deep level diversity on group creativity. Journal of Experimental Social Psychology, 49(5), 822-832.

Harvey, S. (2014). Creative synthesis: exploring the process of extraordinary group creativity. Academy of Management Review, 39(3), 324-343.

Ilevbare, I. M., Probert, D., \& Phaal, R. (2013). A review of TRIZ, and its benefits and challenges in practice. Technovation, 33(2), 30-37

John-Steiner, V. (2000). Creative collaboration. New York: Oxford University press.

Johnstone, K. (1979). Impro: improvisation and the theatre. USA: Routledge/Theatre Arts Books.

Kesting, P., \& Parm Ulhøi, J. (2010). Employee-driven innovation: extending the license to foster innovation. Management decision, 48(1), 65-84.

Koppett, (2001). Training to imagine. Practical improvisational theatre techniques to enhance creativity, teamwork, leadership, and learning. Stylus Publishing, LLC.

Kramer, T. J., Fleming, G. P., \& Mannis, S. M. (2001). Improving face-to-face brainstorming through modeling and facilitation. Small Group Research, 32(5), 533-557.

Nisula \& Kianto (2018). Stimulating organizational creativity with theatrical improvisation. Journal of Business Research. 85, 404-493.

Oldham, G. R., \& Cummings, A. (1996). Employee creativity: personal and contextual factors at work. Academy of Management Journal, 39(3), 607-634.

Onarheim, B., \& Christensen, B. (2011). Idea screening in engineering design using employee-driven wisdom of the crowds. In DS 68-7: Proceedings of the 18th International Conference on Engineering Design (ICED 11), impacting society through engineering design (Vol. 7: Human behaviour in design). Denmark: Lyngby/Copenhagen.

Osborn, A. F. (1963). Applied imagination: principles and procedures of creative problem-solving. Scribner.

Paulus, P. B., \& Yang, H. C. (2000). Idea generation in groups: a basis for creativity in organizations. Organizational Behavior and Human Decision Processes, 82(1), 76-87.

Provost, L. P., \& Sproul, R. M. (1996). Creativity and improvement: a vital link. Quality Progress, 17-23.

Robbins, P., \& O'Gorman, C. (2015). Innovating the innovation process: an organisational experiment in global pharma pursuing radical innovation. $R \& D$ Management, 45(1), 76-93. 
Romero, D., \& Molina, A. (2009). Value co-creation and co-innovation: linking networked organisations and customer communities. In Working Conference on Virtual Enterprises (pp. 401-412). Berlin, Heidelberg: Springer.

Savransky, S. D. (2000). Engineering of creativity: introduction to TRIZ methodology of inventive problem solving. CRC Press.

Sawyer, R. K., \& DeZutter, S. (2009). Distributed creativity: how collective creations emerge from collaboration. Psychology of Aesthetics, Creativity, and the Arts, 3(2), 81-92.

Spolin, V. (1977). Improvisation for the theatre: a handbook of teaching and directing techniques. UK: Pitman Publishing Limited.

Styhre, A. \& Sundgren, M. (2005). Managing creativity in organizations: critique and practices. Basingstoke: Palgrave Macmillan.

Tidd, J. \& Bessant, J. (2009). In: Managing Innovation: Integrating Technological, Market and Organizational Change. Wiley, New York.

Weick, K. E. (1993). Organisational redesign as improvisation. In G. P. Huber, \& W. H. Click (Eds.), Organisational change and redesign. Ideas and insights for improving performance (346-379). Oxford University Press.

West, J., \& Bogers, M. (2014). Leveraging external sources of innovation: a review of research on open innovation. Journal of Product Innovation Management, 31(4), 814-831.

West, M. A., \& Altink, W. M. M. (1996) Innovation at work: individual, group, organizational and sociohistorical perspectives. European Journal of Work and Organizational Psychology, 5, 3-11.

West, M. A., \& Richter, A. W. (2011). Team climate and effectiveness outcomes. California: SAGE Publications Inc.

Von Hippel, E. (1988). The sources of innovation. New York: Oxford University Press.

Yanow, D. (2001). Learning in and from improvising: lessons from theatre for organisational learning. Reflections, 2(4), 58-65.

Yin, R. K. (1994). Discovering the future of the case study method in evaluation research. Evaluation practice, 15(3), 283-290.

Yin, R. K. (2003). Case study research: design and methods (3rd ed.). Thousand Oaks: Sage. 
APPENDIX I: Events in the improvisational theatre workshop

\begin{tabular}{|l|l|}
\hline Exercise and its source & Form \\
\hline Celebrate failure (training courses, combined) & group \\
\hline Invisible balls with words and movement (training course, combined) & group \\
\hline “Travelling" and telling a common story one word at time (training course) & pair \\
\hline Disagree/agree, accept and add an offer (Johnstone 1979; Koppett 2001) & pair \\
\hline Yes, but.... vs. Yes, and...(Johnstone 1979; Koppett 2001) & two groups \\
\hline Telling a story one word at time (Johnstone, 1979; Koppett 2001) & group \\
\hline Group counting (Koppett 2001) & group \\
\hline Group jumping (Koppett 2001) & group \\
\hline
\end{tabular}

\section{Authors' bios}

Anna-Maija Nisula. D.Sc. (Econ. \& Bus. Adm.) is a post-doctoral researcher at the School of Business and Management at Lappeenranta University of Technology, Finland. Her research focus is knowledge management, creativity and innovation, organizational behaviour and organizational learning. Her work has been published in the International Journal of Human Resource Management, Leadership and Organization Development Journal, Creativity and Innovation Management, Journal of Business Research and the Interdisciplinary Journal of Information, Knowledge and Management.

Aino Kianto, DSc (Economics and Business Administration), Lappeenranta University of Technology, School of Business and Management, is a Professor of Knowledge Management at the School of Business and Management at Lappeenranta University of Technology. Her teaching and research focus on knowledge management, intellectual capital, creativity, innovation and organizational renewal. She has authored and co-authored more than 100 academic publications on these topics and received several awards for research excellence. 